\title{
PSYCHOLOGY
}

\section{TOLERANCE OF UNCERTAINTY AND EXECUTIVE DYSFUNCTION IN PEOPLE WITH PSYCHOLOGICAL TRAUMA}

\author{
Serhii V. Lytvyn \\ Postgraduate student, Taras Shevchenko National University of Kyiv, Ukraine, \\ ORCID ID: https://orcid.org/0000-0002-2859-1530
}

DOI: https://doi.org/10.31435/rsglobal_wos/30062020/7125

\section{ARTICLE INFO}

Received: 08 April 2020

Accepted: 11 June 2020

Published: 30 June 2020

\section{KEYWORDS}

tolerance to uncertainty, intolerance to uncertainty, interpersonal intolerance to uncertainty,

psychological trauma, executive dysfunctions, somatic marker, the Stroop effect.

\begin{abstract}
The aim of this study was to determine the effect of tolerance of uncertainty on the executive functions in people with psychological trauma. To study the neuropsychological correlates of tolerance of uncertainty in people with psychological trauma, 55 subjects aged 21 to 66 years (25 men and 30 women) were involved. The control sample included 56 subjects aged 22-67 years (21 men and 35 women). Research methods: "New questionnaire of tolerance-intolerance of uncertainty", "Iowa Gambling Task", Clinician-Administered PTSD Scale for DSM-IV (CAPS-DX), Method of verbal-color interference (Stroop test). Results: psychological trauma causes a decrease in the level of tolerance of uncertainty (ToU), an increase in the level of intolerance of uncertainty (IoU) and an increase in the level of interpersonal intolerance of uncertainty (IIoU). ToU can be seen as a protective factor in the case of psychological trauma. ToU can alleviate the manifestations of executive dysfunction (when treating both ambivalent and indeterminate stimuli) in people with a history of psychological trauma. IoU can be considered as a psychological construct that interferes with the normal functioning of executive functions in the control group (persons without a history of psychological trauma). Psychological trauma causes an increase in the level of IIoU in a way that is not associated with executive dysfunction.
\end{abstract}

Citation: S. V. Lytvyn. (2020) Tolerance of Uncertainty and Executive Dysfunction in People with Psychological Trauma. International Academy Journal Web of Scholar. 6(48). doi: 10.31435/rsglobal_wos/30062020/7125

Copyright: (C) 2020 S. V. Lytvyn. This is an open-access article distributed under the terms of the Creative Commons Attribution License (CC BY). The use, distribution or reproduction in other forums is permitted, provided the original author(s) or licensor are credited and that the original publication in this journal is cited, in accordance with accepted academic practice. No use, distribution or reproduction is permitted which does not comply with these terms.

Introduction. The problem of executive dysfunction in people with psychological trauma is important for a holistic understanding of the neuropsychological mechanisms of mental disorders. People with psychological trauma are often more hostile to uncertainty (have a low level of ToU). So the question is: are executive dysfunctions associated with decreased $\mathrm{ToU}$ in people with psychological trauma?

\section{Materials and Methods.}

The construct of ToU includes psychological components (the ability to comfortably experience the lack of explicit information; the ability to hold conflicting (ambivalent) judgments; the ability to work with full dedication without being certain about the result; the ability to experience constant things as a process; the ability to comfortably accept other people's subjectivity, readiness for spontaneity and encouragement of freedom in close relationships, awareness that certain aspects of 
reality are independent from human will and desires, tolerance for unknowability, ability to calmly experience ambiguity and incompleteness in communication, comfortable experience of situations in which important people's opinions are not clear, awareness of the relativity of conventional norms and "the play-element of culture", awareness of their own ways of bringing certainty (which work automatically) [8, 16]. The construct of ToU includes neuropsychological components as well (systems of functions which aim to organise and control the behavior, the somatic markers system) [9, $10,11,13,15,18,22,26]$.

Traditionally, in studies of ToU, this construct is divided into two general types:

- tolerance for ambiguity, contradictions. In other words, the retention of these contradictions (dialectical level of thinking) without trying to immediately identify them (choose one thing and deny the other);

- tolerance to the lack of (explicit) information. In other words, openness to new experiences and flexibility as opposed to the acceptance of determinism and fatalism, the creation of rituals and rigid systems $[8,14,16]$.

If we consider executive functions as a collective term that characterizes the work of the orbitofrontal cortex, ventromedial cortex and dorsolateral cortex, then, for further research, these functions should be differentiated in the context of ToU $[4,12,17]$.

The focus is primarily on such executive functions as planning, selection, adherence and change of behavioral strategy, ensuring spontaneity and flexibility of behavior (aspects of tolerance to uncertainty provided by the dorsolateral cortex); future orientation and inhibition of automatic reactions (aspects of tolerance to uncertainty provided by the orbitofrontal cortex); a somatic markers system that is closely linked to decision-making in situations where explicit learning is not available (the aspect of ToU provided by the functioning of the ventromedial cortex) $[4,13,15,17,18]$.

With the help of theoretical analysis, the main features of the brain organization of behavioral control and management functions in persons with psychological trauma were outlined. Behavioral management and control functions (executive functions) in persons with a history of psychological trauma have a pathological brain organization due to a decrease in GABAergic transmission and increased dopaminergic transmission. As a consequence, the work of the behavioral control system is disrupted (in situations that require the processing of ambivalent stimuli, such as the conflict between current interest and long-term benefits is the result of reducing the efficiency of the orbitofrontal cortex). The somatic markers system is also affected (in situations of information deficit, which require making adaptive decisions based on internal processes is the result of reducing efficiency of the ventromedial cortex). Thus, it can be stated that persons with a history of psychological trauma have manifestations of executive dysfunctions $[1,3,4,7,19,24,27]$.

Selection of previously unresolved parts of the problem: neuropsychological mechanisms for reducing the level of ToU in people with emotional trauma remain currently inexhaustible. Are executive dysfunctions caused by emotional trauma associated with decreased ToU? Which aspect of executive dysfunctions plays a significant role in reducing ToU (processing ambivalent incentives or making decisions in the context of the information deficit)?

The aim of the study: to detect neuropsychological correlates of ToU in individuals with emotional trauma.

The criteria for inclusion of subjects in the clinical sample were the results of a semistructured interview according to the Clinician-Administered PTSD Scale for DSM-IV (CAPS-DX). To evaluate the level of ToU, the method "New questionnaire of tolerance-intolerance of uncertainty" was used. The Iowa gambling task (IGT) and the Stroop test were used to access executive functions.

According to the above-mentioned division of ToU into two aspects (tolerance to ambivalence and tolerance to lack of information), neuropsychological methods of studying executive functions were chosen. Thus, the technique of verbal-color interference (the Stroop test) appeals to such an aspect of ToU as tolerance to ambivalence, because the stimulus material of the Stroop test contains just ambivalent stimuli (font color interferes with the verbal designation of color). The IGT, in turn, appeals to such an aspect of ToU as tolerance for lack of information, because the stimulus material of the IGT contains a task in which alternatives must be randomly chosen.

The obtained data were processed by comparative (Mann-Whitney test) and correlation (Spearman's correlation coefficient) analysis. 


\section{Results and discussion.}

Results of comparative analysis (comparison of indicators in clinical and control samples):

1) There is a statistically significant difference in ToU between clinical and control samples $(\mathrm{W}=514, \mathrm{p}$-value $=1.439 \mathrm{e}-09)$. In the clinical group there is a significantly lower level of ToU compared to the control group $(36.8<56)$. Thus, it can be argued that psychological trauma leads to a significant reduction in the level of ToU. It can also be assumed that a person with a history of psychological trauma, in turn, seeks certainty, which he/she considers a guarantee of security [4, 24].

2) There is a statistically significant difference in IoU between the indicators in the clinical and control samples $(\mathrm{W}=2800, \mathrm{p}$-value $=1.069 \mathrm{e}-13)$. In the group of subjects who had a history of psychological trauma (clinical) there is a significantly higher level of IoU, than in the control group $(74.8>49.7)$. This phenomenon can be explained as follows: in the period of post-traumatic adaptation there is a tendency to avoid triggers that can provoke a recurrence of a traumatic situation. Persons with a history of psychological trauma tend to divide the world into "safe" and "dangerous", "good" and "bad" parts. Such forms of adaptation are obviously manifestations of IoU [1, 2, 5, 28].

3) There is a statistically significant difference in IIoU between the indicators in the clinical and control samples $(\mathrm{W}=2230$, $\mathrm{p}$-value $=4.7 \mathrm{e}-05)$. The obtained results indicate that there is a significant difference between the clinical and control groups in terms of IIoU (authoritarianism). Indicators of IIoU in the clinical group are significantly higher than in the control group $(35>26.6)$. Because the need of security (which cannot be satisfied in the affected person) is primary, people with trauma tends to overregulate the relationship (roles or rules) in order to achieve security. However, this security significantly suppresses spontaneity in the relationship and can eventually destroy them $[1,4,5]$.

4) There is no statistically significant difference in the IGT total score (efficiency of the somatic markers system) between the clinical and control samples $(\mathrm{W}=1658.5$, $\mathrm{p}$-value $=0.4863)$. Based on the obtained data, it is necessary to refute the hypothesis that the somatic markers system significantly loses effectiveness due to psychological trauma. There are no significant differences between the indicators in the clinical and control groups in the IGT $(1843.1 \sim 1736.6)$. This empirical result indicates that individuals with a history of psychological trauma retain the ability to rely on somatic markers in decision-making.

5) There is a statistically significant difference in the Stroop test total time (indicator of the brain system of behavioural control and management) between clinical and control samples ( $W=$ 2679, $p$-value $=1.878 e-11$ ). The more time the person spends on the Stroop test, the greater is the severity of executive dysfunctions. Since there is a significant difference in the indicator "total time of the Stroop test" (the average in the clinical sample is much higher than the average in the control: 276 $>186$ ), it can be stated that psychological trauma significantly impairs the performance of executive functions. Functions of management and control of behavior during the Stroop test allow the person to perceive and respond to stimuli that contain contradictions (word-color interference) [3].

6) The difference in the time of the I and II Parts in the Stroop test (severity of the interference effect in the Stroop test) is a statistically significant in the clinical and control samples $(\mathrm{W}=1185.5, \mathrm{p}$ value $=0.03676)$. Representatives of the clinical group have a significantly lower rate than those in the control group $(7.7<19.6)$. An unexpected tendency is a reduction in the time difference between the first and second stages of the Stroop test in people with psychological trauma; it can be understood only by the second indicator: a large number of errors observed in the clinical sample $(20.5>4)$. Probably the solution lies in the mechanism of the protective reaction, which arises in response to conflicting stimuli. It is possible that a representative of the clinical group, who unsuccessfully tries to unravel the problems of the second stage of the Stroop test and makes mistakes, eventually despairs and begins to pass the test indifferently (violating the instructions), which reduces the duration of the second stage before the first. Prolongation of the first stage, in turn, may be caused by delayed workability.

7) There is a statistically significant difference in the number of errors in the Stroop test (severity of the effect of interference in the test) between the indicators in the clinical and control samples $(\mathrm{W}=2726$, $\mathrm{p}$-value $=2.434 \mathrm{e}-12)$. The ability to maintain a mental course and complete the initiated work (indicators of executive functions) is manifested in the Stroop test by following the instructions. Accordingly, the tendency to be distracted from the performance, the tendency to violate the instructions can be considered as a manifestation of executive dysfunctions, which is evident in the clinical group [20]. 
The results of correlation analysis for the control sample:

To search for neuropsychological correlates of ToU, we use correlation analysis. This procedure involves the establishment of a direct or inverse linear relationship between two or more variables.

First of all, consider the neuropsychological correlates of the construct ToU on the material of the control sample:

- Inverse relationship with the number of errors during the Stroop test $(-0.37 * *)$. The first pattern is the inverse relationship between the level of ToU and the number of errors during the Stroop test $\left(-0.37^{* *}\right)$. Thus, the higher is the level of ToU, the fewer mistakes the person makes when processing stimuli that contain verbal-color interference. By definition, such a construct as ToU includes the ability of a person to tolerate not only stimuli that involve a lack of information, but also those stimuli that have internal contradictions or contain contradictions. Taking into account that word-color interference in the second stage of the Stroop test is just an example of a stimulus that contains internal contradictions, we can assume that one of the neuropsychological correlates of ToU in the control sample is the brain's ability to process ambivalent stimuli and maintain behavior control).

Next, consider the neuropsychological correlates of the IoU construct on the control sample:

- Inverse relationship with the sum of the scores on the IGT (-0.3*). Hostile attitudes to uncertainty impair the effectiveness of tasks that contain a lack of explicit information. As a result, people with a high level of IoU have a reduced ability to make adaptive decisions (decisions in conditions of information deficit). Thus, a possible neuropsychological correlate of IoU in the control sample is the difficulty in processing uncertain stimuli (namely, reduced efficiency of decision-making in conditions of information deficit) [23].

- Direct relationship to the time of the Stroop test performing $(0.43 * *)$. The next pattern is the direct relationship between the level of IoU and the total time of the Stroop test performance $(0.43 * *)$. Thus, the higher level of IoU person has, the more time he/she needs to process stimuli that contain word-color interference. Most of the resources of the brain system of behavioural control and management are spent on emotional self-regulation, resulting in an increase in the latency period required to process ambivalent stimuli. However, since the correlation does not indicate the direction of the connection, we can assume another explanation which imply cognitive issues. The point is that possible cognitive difficulties associated with the processing of ambivalent stimuli lead to the accumulation of negative experience after dealing with ambiguity and ambivalence. One way or another, but it should be concluded that a possible neuropsychological correlate of IoU in the control sample is the difficulty of processing ambivalent stimuli (namely, the growth of the latent period preceding the processing of ambivalent stimulus) [21].

- Direct correlation with the number of errors during the Stroop test $(0.5 * *)$. The next pattern is the direct relationship between the level of IoU and the number of errors during the Stroop test $(0.5$ **). Therefore, the higher level of IoU person has, the more mistakes he/she makes when processing stimuli that contain word-color interference. Thus, one of the neuropsychological correlates of IoU in the control sample is problems with tasks that require inhibition of the automatic response and the generation of adaptive response (methods which belong to the group of tests "go-no go"). control sample:

Next, consider the neuropsychological correlates of the IIoU construct on the material of the

Inverse relationship with the sum of the scores on the IGT $\left(-0.3^{*}\right)$. The inverse relationship between the success in the IGT and the level of IIoU $\left(-0.3^{*}\right)$ can be explained at the following level of generalization: the effective functioning of the somatic marker system (which enables the successful IGT) requires the ability to listen to person's own somatic reactions that accompany the experience of emotions. On the other hand, the ability to empathize with other people is closely related to the ability to understand one's own emotions and realize one's own uncomfortable bodily manifestations (individuals who are insensitive to their own somatic sensations, including pain and discomfort, are unable to empathize with other people's suffering). Thus, the effective functioning of the somatic markers system makes it impossible to show authoritarianism, ie IIoU in the control group.

- Direct correlation with the number of errors in the Stroop test $(0.34 * *)$. The next pattern is the direct relationship between the level of IIoU and the number of errors in the Stoop test $(0.34 * *)$. It can be assumed that the increase in the level of IIoU in the control sample is associated with an increase in the frequency of errors in the field of social competences, especially regarding the feelings of others, which are often a source of ambivalence. 
The results of correlation analysis for the clinical sample:

To find neuropsychological correlates of ToU in people with psychological trauma, we use correlation analysis. This procedure implies the detection of a direct or inverse linear relationship between two or more variables.

First of all, consider the neuropsychological correlates of the ToU construct on the material of the clinical sample:

- Direct correlation with the sum of points in the IGT $\left(0.37^{* *}\right)$. The data indicate that ToU is significantly related to the success of the IGT in the clinical sample $(0.37 * *)$. Representatives of the clinical sample have a history of psychological trauma. Given this condition, it should be assumed that a high level of ToU is one of the protective factors in the period of post-traumatic adaptation, which allows to maintain the ability to make adaptive decisions in conditions of uncertainty despite the destructive effects of traumatic events. A high level of ToU allows the subject to listen to somatic markers and, as a result, to make more successful decisions during the IGT.

- Inverse relationship with the performance-time of the Stroop test $(-0.31 *)$. The clinical sample shows that the ToU and the time in the Stroop test are inversely related $(-0.31 *)$. This empirical pattern suggests that the effectiveness of executive functions in the performance of the Stroop test is a potential neuropsychological correlate of ToU in the clinical sample. Psychological trauma is likely to lead to an increase in executive dysfunction, resulting in increased time required for the subject to perform the Stroop test. However, subjects from the clinical sample who have a higher level of ToU show less pronounced executive dysfunction [27].

- Inverse relationship with the number of errors during the Stroop test $\left(-0.44^{* *}\right)$. Based on the data obtained, ToU in the clinical sample is inversely related to the number of errors during the Stroop test $\left(-0.44^{* *}\right)$. The higher is the level of ToU in a person experiencing a period of posttraumatic adaptation, the fewer errors he/she makes when processing ambivalent stimuli. ToU is likely to alleviate the effects of executive dysfunction caused by psychoogical trauma [6].

Next, consider the neuropsychological correlates of the construct of intolerance to uncertainty in the clinical sample:

- Direct relationship to the performance-time of the Stroop test $(0.31 *)$. The next pattern is the direct relationship between the level of IoU in the clinical sample and the total time of the Stroop test $(0.31 *)$. It can be assumed that $I o U$ in people with psychological trauma exacerbates the manifestations of executive dysfunction. The high level of IoU in people with psychological trauma forces them to avoid uncertainty and rely on the external structure, which allows to restrain the activity of the executive functions. Accordingly, there is cognitive rigidity, which increases the performance-time of the Stroop test.

- Direct correlation with the number of errors during the Stroop test $(0.33 *)$. For a holistic interpretation of the above trend, other indicators of the Stroop test should also be considered, namely: there is a significant direct linear relationship between the level of IoU in the clinical sample and the number of errors in the Stroop test $(0.33 *)$. Such assumptions prompt a closer look at the structure of the protective response that arises in response to uncertainty. Most often, negative attitudes toward uncertainty in people with psychological trauma include fear and anxiety, forcing them to view uncertain situations as risky. If we take as a basis the "freeze-run-fight" response model, we can assume the appearance of reactions of irritation and anger, which cause indifference and hostility to the tasks of the Stroop test. The trigger for this reaction of anger seems to be the helplessness that occurs in people with executive dysfunctions as a result of facing an ambivalence situation. The inability to maintain a mental course and complete the work started (signs of executive dysfunctions) is manifested in the Stroop test due to violation of the instructions. Accordingly, the tendency to be distracted from the tasks of the test can be considered as a manifestation of executive dysfunctions in persons with psychological trauma. It is important to emphasize that the high level of IoU in people with psychological trauma significantly exacerbates the manifestations of these executive dysfunctions (in particular, causes an increase in the number of errors in processing of ambivalent stimuli).

\section{Conclusions.}

1. $T o U$ in the clinical sample is more strongly associated with executive dysfunction than in the control sample. If the ToU allows the subjects of the control sample to avoid errors in the processing of ambivalent stimuli, then the value of this construct for people with psychological trauma increases significantly. According to the results of the current study, psychological trauma causes 
executive dysfunctions that are associated with the processing of ambivalent stimuli, but does not affect the process of processing indeterminate stimuli. However, both the first and the second type of stimuli are studied better from the clinical sample, provided they have a high level of ToU. Thus, we can consider $T o U$ as a protective factor in the case of psychological trauma. ToU can alleviate the manifestations of executive dysfunction (when treating both ambivalent and indeterminate stimuli) in people with a history of psychological trauma [19].

2. IoU in the control sample is more strongly associated with executive functions than in the clinical. Representatives of the control group, who have a high level of IoU, show a decline in the results of tests for executive functions. Thus, IoU can be considered as a psychological construct that interferes with the normal functioning of executive functions in the control sample. However, in the clinical sample this tendency is much weaker. Although psychological trauma leads to a significant increase in the level of IoU, executive dysfunction appear to occur in the clinical sample regardless of this construct (at least in relation to the processing of uncertain stimuli).

3. IIoU in the control sample is associated with executive functions, while in the clinical sample this construct is determined by other factors [25]. Obviously, psychological trauma causes an increase in the level of IIoU in a way that is not associated with executive dysfunctions.

\section{REFERENCES}

1. Boswell, J. F., Thompson-Hollands, J., Farchione, T. J., \& Barlow, D. H. (2013). Intolerance of uncertainty: A common factor in the treatment of emotional disorders. Journal of clinical psychology, 69(6), 630-645. https://doi.org/10.1002/jclp.21965

2. Carleton, R. N., Duranceau, S., Shulman, E. P., Zerff, M., Gonzales, J., \& Mishra, S. (2016). Self-reported intolerance of uncertainty and behavioural decisions. Journal of behavior therapy and experimental psychiatry, 51, 58-65. https://doi.org/10.1016/j.jbtep.2015.12.004

3. Cisler, J. M., Wolitzky-Taylor, K. B., Adams Jr, T. G., Babson, K. A., Badour, C. L., \& Willems, J. L. (2011). The emotional Stroop task and posttraumatic stress disorder: a meta-analysis. Clinical psychology review, 31(5), 817-828. https://doi.org/10.1016/j.cpr.2011.03.007

4. Cozolino, L. (2017). The Neuroscience of Psychotherapy: Healing the Social Brain (Norton Series on Interpersonal Neurobiology). WW Norton \& Company.

5. de Jong-Meyer, R., Beck, B., \& Riede, K. (2009). Relationships between rumination, worry, intolerance of uncertainty and metacognitive beliefs. Personality and Individual Differences, 46(4), 547-551. https://doi.org/10.1016/j.paid.2008.12.010

6. Fergus, T. A., Bardeen, J. R., \& Wu, K. D. (2013). Intolerance of uncertainty and uncertainty-related attentional biases: Evidence of facilitated engagement or disengagement difficulty? Cognitive therapy and research, 37(4), 735-741. https://doi.org/10.1007/s10608-012-9509-9

7. Garfinkel, S. N., \& Liberzon, I. (2009). Neurobiology of PTSD: A review of neuroimaging findings. Psychiatric Annals, 39(6). https://doi.org/10.1016/j.jpsychires.2019.11.012

8. Gusev, A. I., \& Gusev, A. I. (2009). Tolerantnist do neviznachenosti yak chinnik rozvitku identichnosti osobistosti [Tolerance for uncertainty as a factor in the development of personal identity] (Doctoral dissertation, Derzhavniy zaklad «Universitet menedzhmentu osviti APN Ukrayini»).

9. Kornilov, S., Krasnov, E., Kornilova, T., \& Chumakova, M. (2015). Individual Differences in Performance on Iowa Gambling Task are Predicted by Tolerance and Intolerance for Uncertainty. In EAPCogSci.

10. Kornilova, T. V., Chumakova, M. A., \& Kornilov, S. A. (2018). Tolerance and intolerance for uncertainty as predictors of decision making and risk acceptance in gaming strategies of the Iowa gambling task. Psychology in Russia, 11(3), 86. https://doi.org/10.11621/pir.2018.0306

11. Krain, A. L., Hefton, S., Pine, D. S., Ernst, M., Xavier Castellanos, F., Klein, R. G., \& Milham, M. P. (2006). An fMRI examination of developmental differences in the neural correlates of uncertainty and decision-making. Journal of Child Psychology and Psychiatry, 47(10), 1023-1030. https://doi.org/10.1111/j.1469-7610.2006.01677.x

12. Lezak, M. D., Howieson, D. B., Loring, D. W., \& Fischer, J. S. (2004). Neuropsychological assessment. Oxford University Press, USA.

13. Luhmann, C. C., Ishida, K., \& Hajcak, G. (2011). Intolerance of uncertainty and decisions about delayed, probabilistic rewards. Behavior Therapy, 42(3), 378-386. https://doi.org/10.1016/j.beth.2010.09.002

14. Lushyn, P. V. (2016). Posttravmaticheskiy rost i usloviya ekologichnogo soprovozhdeniya travmaticheskih perezhivaniy [Post-traumatic growth and environmentally friendly support for traumatic experiences]. Naukoviy chasopis natsionalnogo pedagogichnogo universitetu imeni MP Dragomanova. Seriya 12: Psihologichni nauki, (4), 11-25.

15. Lytvyn, S. (2018). The system of executive functions as a neuropsychological correlate of tolerance to uncertainty. Psychological journal, 4(10), 29-46. https://doi.org/10.31108/1.2018.10.20.2 
16. Lytvyn, S. (2019). Tolerance to uncertainty as a psychological construct. Psychological journal, 5(1), 90107. https://doi.org/10.31108/1.2019.1.21.6

17. Malysheva, K. O. (2012). Neyroanatomichni korelyati mozkovih funktsiy programuvannya, regulyatsiyi ta kontrolyu povedinki [Neuroanatomical correlates of brain functions of programming, regulation and control of behavior]. Zbirnik naukovih prats Institutu psihologiyi imeni GS Kostyuka Natsionalnoyi APN Ukrayini. Problemi zagalnoyi ta pedagogichnoyi psihologiyi, (24, ch. 6), 274-281.

18. Malysheva, K. O. (2013). Prefrontalni viddili kori golovnogo mozku: istoriya novitnih doslidzhen. [Prefrontal cortex: a history of recent research] Problemi suchasnoyi psihologiyi, 19.

19. McEvoy, P. M., \& Mahoney, A. E. (2012). To be sure, to be sure: Intolerance of uncertainty mediates symptoms of various anxiety disorders and depression. Behavior therapy, 43(3), 533-545. https://doi.org/10.1016/j.beth.2011.02.007

20. Mobini, S., \& Grant, A. (2007). Clinical implications of attentional bias in anxiety disorders: An integrative literature review. Psychotherapy: Theory, Research, Practice, Training, 44(4), 450. https://doi.org/10.1037/0033-3204.44.4.450

21. Nelson, B. D., \& Shankman, S. A. (2011). Does intolerance of uncertainty predict anticipatory startle responses to uncertain threat? International Journal of Psychophysiology, 81(2), 107-115. https://doi.org/10.1016/j.ijpsycho.2011.05.003

22. Norwood, E. (2014). The effect of intolerance of uncertainty on attention biases as indicated by performance on the emotional Stroop and dot-probe task (Doctoral dissertation). https://doi.org/10.13016/M2234T

23. Ritter, M. R. (2007). An investigation of intolerance of uncertainty in worry using a gamble preference task (Doctoral dissertation, University of Nevada, Reno).

24. Schienle, A., Köchel, A., Ebner, F., Reishofer, G., \& Schäfer, A. (2010). Neural correlates of intolerance of uncertainty. Neuroscience letters, 479(3), 272-276. https://doi.org/10.1016/j.neulet.2010.05.078

25. Schroeder, P. A., Dignath, D., \& Janczyk, M. (2018). Individual differences in uncertainty tolerance are not associated with cognitive control functions in the flanker task. Experimental psychology. https://doi.org/10.1027/1618-3169/a000408

26. Smirnov, S. D., Chumakova, M. A., Kornilov, S. A., Krasnov, E. V., \& Kornilova, T. V. (2017). Kognitivnaya i lichnostnaya regulyatsiya strategiy resheniya prognosticheskoy zadachi (na materiale IowaGamblingTask) [Cognitive and personality regulation of strategies for solving a prognostic task (based on IowaGamblingTask)]. Vestnik Moskovskogo universiteta. Seriya 14: Psihologiya, (3). https://doi.org/10.11621/vsp.2017.03.39

27. Wever, M., Smeets, P., \& Sternheim, L. (2015). Neural correlates of intolerance of uncertainty in clinical disorders. The Journal of neuropsychiatry and clinical neurosciences, 27(4), 345-353. https://doi.org/10.1176/appi.neuropsych.14120387

28. Zlomke, K. R., \& Jeter, K. M. (2014). Stress and worry: examining intolerance of uncertainty's moderating effect. Anxiety, Stress \& Coping, 27(2), 202-215. https://doi.org/10.1080/10615806.2013.835400 